\title{
NEW TRAINING SCHEMES FOR THE FUTURE EDUCATION IN RAILWAY SECTOR
}

\author{
Dana Sitányiová ${ }^{*}$ and Jaroslav Mašek $^{2}$ \\ ${ }^{1}$ University of Žilina, Faculty of Civil Engineering, Univerzitná 8215/1, 01026 Žilina, Slovakia \\ ${ }^{2}$ University of Žilina, Faculty of Operation and Economics of Transport and Communications, Univerzitná 8215/1, 01026 Žilina, \\ Slovakia
}

\begin{abstract}
Railway transport is a sector that is rapidly developing, changing and being influenced to the maximum extent by the technological development and innovation, among others, thus facing problems in staffing its several domains with appropriate and qualified personnel. This fact, makes the need for changes in training and education of future transport professionals. SKILLFUL project vision is to identify the skills and competences needed by the transport workforce of the future and define the training methods and tools to meet them. Paper focuses on mid-term results of the project, with special focus on railway transport.
\end{abstract}

\section{Introduction}

The transportation sector employs over 10 million persons in the EU today. At the same time, transport is a social sector that is rapidly developing, changing and being influenced to the maximum extent by the development of automation, electrification and greening of transport, among others, thus facing problems in staffing its several domains with appropriate and qualified personnel. This fact, makes the need for changes in training and education content, curricula, tools and methodologies absolutely imperative, incorporating lifelong learning aspects for the professionals in all transports areas. Additionally, the demographic trends (such as population age) are also going to play a key role over the next years, since large groups of professionals taking retirement should be replaced by younger generation of employees. So, an additional challenge is whether enough professionals having the right skills could be attracted to the transportation sector workforce [1].

SKILLFUL project vision is to identify the skills and competences needed by the transport workforce of the future and define the training methods and tools to meet them. Employability is strongly connected by the project to future transport job requirements for all transportation modes and multimodal chains for all levels/types of workers, while all training modes are included and integrated in a balanced way.

SKILLFUL is financed under Horizon 2020, reviewing the existing, emerging and future knowledge and skills requirements of workers at all levels in the transportation sector, to structure the key specifications and components of the curricula and training courses that will be needed to meet these competence requirements optimally in order to achieve European wide competence development. Project results are verified through wide range of pilot courses from all transportation modes Europe wide [2].

Rail is a modern, technologically advanced industry that has an important and growing role. Demand for rail services has increased through significant infrastructure investment, increased demand for passenger and freight services, technological advancement, development in the resources sector and increased customer expectations including customer service standards and reliability. [3]

The rail sector in the next decade will face simultaneously the challenges of an ageing working population, probably leading to workforce shortages. Rail industry needs skilled and capable staff to continue to grow and meet future demand. Increased productivity and attractiveness of rail transport will lead to demand increases and investments such as in new rolling stock from which working conditions are likely to benefit. However, the availability of a skilled and highly motivated labour force in the transport sector is essential for the supply of efficient and competitive transport services. It is vital to continuously improve the skilling and professional development of people across all sectors of the rail industry, at all levels. SKILLFUL project ultimate goal is to establish a suite of training solutions for all transport modes including rail to take the qualification to any desired level.

\section{Future challenges for education}

The aforementioned changes and developments in the transportation sector of Europe are expected to bring changes to the employability of the sector. They are expected to cause the alteration of many jobs (sometimes even their disappearance), as well as the emergence of various new occupations. In the light of this, the education and training sector will need to adapt rapidly and

${ }^{*}$ Corresponding author: dasit@fstav.uniza.sk 
effectively in order to insure training/education provision efficiency and to fulfil new jobs skills and competences requirements effectively. Education will constitute a pivotal role in order to properly drive new potential workers on covering the future and each emerging demand. As a result, new education schemes will become increasingly focused, not just on knowledge, but also on strategic skills that students need to get a job. [4]

In this respect, SKILLFUL project provides a general overview of new and emerging training tools, methodologies, and schemes, which will be the most promising for the transport education provision in the near and distant future. In doing so, new and emerging training facilities were identified and analysed using the broadest possible spectrum at several levels:

- Including a wide knowledge base and relying on multiple knowledge communication channels;

- Including all user groups and areas, such as blue collar workers, white collar workers, engineers, management teams or relevant competent authorities and political boards;

- Considering all forms and levels of education;

- Exploring potential initiatives and innovation proposed by or successfully applied, not necessarily from the transport sector but with emphasis on applicability in the transport sector;

- Exploring potential initiatives and innovation in the whole European region and beyond;

- Considering potential applications to transport workforce education provision for all areas including all transport modes (maritime, rail, road and air), as well as intermodality/cross modality.

To ensure the best coverage of the topic under investigation, the methodology relied on multiple sources of knowledge, respectively:

- A wide consultation of experts - either in the field of transport or education/training or both - form all over the European continent;

- An extensive review of the recent scientific literature;

- A complementary review of literature on local and regional initiative and innovation (grey literature).

Experts were first asked to rate skills and competences importance for the different transport job categories. From this question, it appears that hard and technical skills are of particular importance for low to middle-skilled worked (i.e. blue collar and professional drivers). Of less importance but nonetheless important are language (especially mother tongue mastery), ICT skills and several soft skills such as flexibility/adaptability, proactivity and engagement and interpersonal skills. For the white-collar job profiles, mother tongue mastery, team working/management and proactivity and engagement were rated as very to extremely important while all other skills were seen as fairly important. Noticeable is the fact that technical skills specific to the job were not seen as the most important. [5] Considering the relative high importance dedicated to soft skills, this suggest however that expert attach higher importance to the skills necessary to an effective adaptation to a rapidly evolving workforce than to technical skills by themselves.
For researcher, engineer and manager all skills categories were rated as very important, with the exception of interpersonal skills which were rated as fairly important (but not very to extremely important) for researchers and engineers. For the decisions making job profiles (i.e. authorities - politics), almost all skills were rated as very important with the exception of the skills that are specific to a particular job, ICT skills and innovation/creativity. This is quite consistent with the fact that while decision makers have to acquire a broad and general knowledge.

As for the improvements for specific education type/level, the improvements 'Adding special themes modules', 'Wider use of new training methods', 'Adequate and sufficient practice training', 'Faster adaptation to new legislations, technologies and labour market' and 'Better adequation between education, job requirements and industry' were quite consistently identified for all education type/level. The improvement 'higher versatility, multiskilling, flexibility and knowledge transfer' was proposed for the 'collegeuniversity' category but also - to a lesser extent - for VET education. Finally, the improvement 'Bigger and more specialized offer for in-house training in company' was proposed for in-house training [6].

\section{Most promising training methodologies}

The last aspect considered in research concerned the identification of the most promising training/education tools and methodologies. In total, 12 promising existing, new and emerging tools and methodologies identified by the expert panel in diminishing importance order are the following:

- E-learning (Distance/mobile/connected learning and online learning environment);

- Virtual/augmented reality;

- Gaming environment;

- Human led individualized training (e.g. executive coaching);

- Blended learning;

- Peer led/mentoring learning programme;

- Traditional lectures;

- Networked learning (e.g. social media networking);

- Smart learning technologies: personalized learning processes;

- Scenario/story based learning;

- Training on the job/experiential learning;

- Informal learning.

In the context of the review of the literature, 150 papers and reports were reviewed and analysed (112 from the scientific literature and 38 from the grey one) covering all the training tools, methodologies and schemes thought to be relevant for the SKILLFUL objectives.

Overall, the new and emerging tools and methodologies identified through the literature review were quite similar to those pointed out by the expert panel with some very few exception. Indeed, from the expert consultation, it appears that some standard educational 
tools/methods - that are not necessarily new (e.g. traditional lectures and/or human led individualized training) - are still of great importance and may still usefully be adopted in combination with more recent technologies. [7]

The two major lessons learned from this review are on the one side the necessity to base learning on multiple resources, medias and techniques - as known as the blended learning approach - to insure learning performance and engagement into it and on the other side the necessity to place the learner as a central and active agent of his/her learning - process implicitly understood, for example, under the heutagogical, the authentic/active and/or the discovery-based learning approaches.

Blended learning may be conceived as a new way of education that depends on the use of multiple education resources (typically blended face-to-face learning with other information technology based features) which makes it a powerful approach for creating educational programs that can take into account the individual differences between students and bring different learning methods [8].

Among the recognized and expected benefits of a successful blended learning approach are: increased active and authentic learning experience and performance, enhanced engagement and motivation, broader knowledge and skills (e.g. soft skills) acquisition, etc. [9]. Finally, it is important to note that the benefits of a particular blended learning scheme will primarily depend on the components that are included into it (collaborative/peer-led components will, for example, enhances soft skills such as negotiation of communication skills).

Learner as a central and active agent of his/her learning: more and more, the pedagogical models suggest that the learnings should be conceived as active and proactive processes with a central place offered to the learner constructing his/her own learning experiences. In doing so, the learning experience is thought to be more authentic and leading to an increased learning engagement, motivation and autonomy from the learner as well as to increased performance and broader knowledge acquisition - as, for example, critical thinking, self-reflection, metacognition and soft skills [5].

Another major benefit is that it involves the learner in realistic requirements and scenario work practices that are aligned to authentic situation and hence better prepared them for personal life accomplishment and for the workplace and to become a lifelong autonomous learner. As compared to traditional educational models - with the learner considered as a passive recipient of learning content - this implies a major revolution and an essential mental shift in the way teachers and learners roles have to be considered.

All 12 tools, methods and supportive technologies presented above are thought to serve the purpose of these two components (i.e. blended learning and placing the learner at the center of his./her learning) and to facilitate their effective implementation. However each of these categories present benefits and drawback and cannot be seen as a panacea for meeting all learning requirements. Instead, it is the well-designed and well-thought combination of several methods - adapted to the learning content as well as to the learner needs - that ensured effectiveness. It is important to note that the rapid developing technology will increasingly impact future workforce skills and competences development in two ways: firstly, as it exerts pressure for change because the new technologies demand a new set of skills and, secondly, as it provides opportunities for transforming pedagogy because it provides access to information, networks for communication, and new means of presenting learning [6].

\section{Critical review of the educational and training systems and mechanisms in the transportation sector}

The one of the aims of the project was to critically review the current practice of skills development for the needs of all transport modes in EU and beyond in order to gain a better understanding of existing training schemes and programmes/courses, their content and targeted audience, as well as the training provider and/or programme owner.

As a result, SKILLFUL is able to identify potential gaps in the availability of training schemes and programmes when looking at job categories in the whole transport sector including rail. Templates were designed and surveys organized to collect information on existing training schemes and programmes/courses in targeted countries for all transport modes (road, air, maritime and rail) [2].

The templates follow the three management levels for transport planning and operations [7], namely: strategic, tactical and operational. This was originally developed for the rail sector but is applicable to all sectors.

Strategic includes long term planning of company development. Decisions made at this level set the strategic goals of the company, which include assessment resources, strategic changes in the company structure, redesign and reconstruction of infrastructure, relocation of railway facilities, construction of new rail lines, acquisition of new resources and technologies, etc. This is the highest level of management in railway organizations. Although the decisions made at this level are capital intensive they should provide the minimum amount of required resources for "normal operation" [8].

Tactical includes medium term planning. At this level all the plans, timetables and schedules are developed. As stated by [9] tactical planning is "to ensure, over a medium term horizon, an efficient and rational allocation of existing resources in order to improve the performance of the whole system". At this level capacity research analysis of congestion and performance assessment are conducted.

Operational includes short term planning, which might be executed over the same day of service delivery. At this management level the plans, timetables and schedules are implemented on a "day-to-day" basis in order for the system to provide the service effectively [10, 11].

A career matrix was designed for each transport mode, specifying job categories under each management level. 
To complete the template, different types of training schemes and programmes were identified. They include: College; University; Professional Training; Apprenticeships; VET \& CVET; Others. Space has been provided within the template for examples of training providers and/or programme owners to be listed, as well as for examples of existing training schemes and programmes to be given. These templates were developed by the partners involved in the project and external contributors, using their expertise in each of the transport modes, in order to identify the existing job categories for each transport mode. The templates were circulated to all SKILLFUL partners, external authorities and stakeholders. Templates were distributed to each country: for each mode and each level, a number of job categories were identified. A comprehensive set of information has been gathered and analysed for 16 countries: Australia, Belgium, Bulgaria, China, Germany, Greece, Ireland, Italy, The Netherlands, Poland, Portugal, Romania, Slovakia, Spain, Sweden and the UK.

A summary report has been produced for every country as part of the analysis (Deliverable D2.1) to provide a brief insight on the content of training schemes and programmes identified. The text below attempt to summarise the gaps found during the analysis. However, it must be noted that it is very difficult to draw any conclusions on the gaps existing in countries as information was difficult to find. Training may be available in some countries for which we have identified gaps but we were unable to find the information on the training. In addition, training on specific course content was very difficult to obtain: in many cases only the title of courses was available and detailed information was not available. Therefore, any conclusions drawn must be treated with considerable caution [2].

High response to demand (United Kingdom)

High supply of rail oriented university degree programmes.

Comprehensive training system for rail in place.

Apprenticeship scheme in place.

Many certified companies provide courses to meet the needs for daily operation.

Easy access to information.

Information available in a living world language.

Average response to demand (Australia, China, Portugal, Romania, Spain, Italy, Germany, Bulgaria, Belgium)

Average supply of rail oriented university degree programmes.

A comprehensive training system for rail in place.

Apprenticeship scheme not in place. [11]

There are a reasonable number of certified companies providing courses to meet the needs for daily operation.

Challenging to access information.

Information unavailable in a living world language.

Low response to demand (Ireland, Poland, Slovakia, Greece)

A small amount of rail oriented university degree programmes.

Apprenticeship scheme not in place.

Monopoly by a single rail company providing training for jobs in rail.
In-company training - information not disclosed to external parties.

None or a small number of certified companies providing courses to meet the needs for daily operation.

Uneasy access to information.

Information unavailable in a living world language.

\section{Others (Sweden, the Netherlands)}

Not enough information available.

Difficult to analyse and conclude.

Generally it can be said that here is a sufficient amount of university degree courses (for example: BSc or MSc in railway engineering) including, courses for the maintenance of rail vehicles, locomotive engineers, signalling inspectors, sale assistants or administrative assistants.

Significant gaps are demonstrated in college and apprenticeships, where for all work categories these courses are not present. There is also a deficiency in professional training and VET \& CVET. With regards to professional training, there are only courses for the job categories of track inspector, maintenance of rail vehicles, locomotive engineer and train crew. Only those training to be track inspectors, timetable planners, train crew members, signaling inspectors, sales assistants and administration managers have the possibility of taking CET \& CVET.

At the tactical level, it is revealed that there are small amount of courses provided for the infrastructure planner, vehicle design engineer or timetable planner.At the operational level, usually the only degree courses available are designed for training track inspectors and research/teaching assistants, as a result, more courses should be provided.

There are not have enough courses specializing in the rail industry in general. The courses are either very general or specialized in non-rail areas, for example, the civil engineering or mechanical engineering course. Students take degrees in other sector, with a focus on transportation. At the operational level many times one rail company have a monopoly in terms of rail service provision, train their drivers and crew members. However, no information is available online as this training is provided in-house.

\section{Pilot courses}

The one of objectives of SKILLFUL project is to design appropriate training/education modules for the Transport sector to fulfil emerging and foresighted required competences and skills. In the context of previous steps, five types of training/educational schemes for various types of workers in all transport modes were designed to be tested as pilot training by partners as follows:

- Transport infrastructure operators' training schemes. Operators need new skills and competences to catch up with emerging technologies. For them lifelong learning, with emphasis on new technologies, constitutes a necessity. But they typically have very little available time as they work under pressure and in tight shifts. Thus, for them webinars and other ICT- 
based training (and certification through web proctoring) schemes might be more appropriate;

- Young scientists' seminars as a joint initiative of ECTRI, FERSI and FEHRL from all Transportation sectors;

- Lifelong training schemes for low to middle-skilled segments of transport professionals;

- Interdisciplinary thematic courses on key technologies, services and trends with a cross modal dimension and/ or where important know-how can be transferred from one mode training to another one;

- Pan-European Transport master curriculum. A first core syllabus will be realised towards a PanEuropean Transport Engineering master. Trials of trans-national specialty courses will be tested to allow students from one country to attend courses from another university within their master degree.

Several courses were developed for rail sectors (or as multimodal too) as follows:

- The management of stress and fatigue in Air and Rail Traffic Management

- Authorised Economic Operator (AEO) and safe supply chains

- Security in transport: influences of new media \& digitalisation

- Advanced intermodal operations and logistics

- The role of Big Data in understanding travel behaviour, traffic and developing policy

- Towards global freight forwarders: New training scheme based on future scenarios

- Greening and electrification of transport module

- Rail operations, signals and model operations through simulation, offered by TUB, IST, UNEW for middle and high-skilled professionals.

\section{Conclusions}

1. All developments, relate to and affecting transportation, whether they relate to technological discoveries and developments, or to social and economic factors, directly affect also the employability, as well as the education and training needs of professionals in the transportation sector;

2. Some existing occupations are expected to change, fall dramatically or even disappear, some new professions are going to make their appearance to meet any emerging needs;

3. A number of gaps have been identified in relation to training. At the same time, a number of new training tools and technologies have also been identified;

4. The availability of technology in the education sector means that approaches using Virtual Learning Environments are now more possible: opening the potential to allow workers to retrain and up-skill. In addition, there have been a number of developments in relation to gamification and simulation which could be adopted in training for automation or in relation to cybersecurity;
5. It is expected that a number of these methodologies will be tested in the pilot training courses. The impact of these methods has not generally been quantified so pilots will offer an opportunity to test the methodologies;

6. More information on project can be found at http://skillfulproject.eu/

This paper is published within the implementation of the project SKILLFUL - Skills and competences development of future transportation professionals at all levels, funded under Horizon 2020 - Research and Innovation programme. H2020-MG-2016-SingleStageINEA - GA no. 723989 .
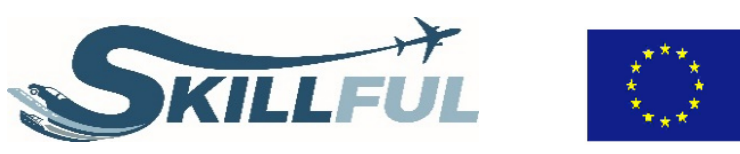

\section{References}

1. SKILLFUL consortium. 2017 Deliverable D1.1: Retrieved from:

http://skillfulproject.eu/library?id=7603

2. SKILLFUL consortium. 2017 Deliverable D2.1 Best practice on current and emerging training schemes, methodologies and tools in the transport sector and mapping to future training requirements and scenarios.

3. M. Azhar, S. Mustapa, M. Ibrahim, A. Yusoff. Procedia - Social and Behavioral Sciences, Vol. 204. Pages 127-135. (2015).

4. N. Canning, Journal of Further and Higher Education, Vol. 34 (No.1), 59-71. Routledge. Retrieved December 13, 2016, from http://www.tandfonline.com/doi/abs/10.1080/03098 770903477102. (2010).

5. L. M. Blaschke, S. Hase. Heutagogy. Springer Berlin Heidelberg. Retrieved December 13, 2016, from http://link.springer.com/10.1007/978-3-662-47724-3 Pages 25-40. (2016).

6. V. Hannon, A. Patton, J. Temperley, M. Stevenson. Developing an Innovation Ecosystem for Education. White Paper. Cisco, Innovation Unit. (2011).

7. M. Marinov, I. Sahin, S. Ricci, G. Vasic-Franklin, Research in Transportation Economics, Vol. 41(No. 1). Pages 59-75. (2013)

8. J. Pachl, T. White. Implementation of Heavy Haul Technology for Network Efficiency. Pages 6-69. (2003).

9. T. Crainic, G. Laporte. (1997). European journal of operational research, Vol. 97(No.3), pages 409-438. (1997)

10. J. Camaj, M. Kendra, J. Lalinska. International Educational Technology Conference, Chicago, IL, USA, IETC 2014. 176. 659-666. (2014).

11. J. Camaj, A. Dolinayova, J. Danis, M. Kendra. ICERI: 9th International Conference of Education, Research and Innovation. 5822-5831. (2016). 